\title{
On Specific Character of Mathematical Education Content Selection at Subject-Specialised School
}

\author{
Irina Lovyanova* \\ Chair of Mathematics and Methods of Mathematics Teaching, Bogdan Khmelnitsky Cherkassy National University, Cherkassy, Ukraine \\ *Corresponding author: lira7-1-8@mail.ru
}

Received September 27, 2013; Revised October 13, 2013; Accepted November 22, 2013

\begin{abstract}
The article dwells on the issues of teaching mathematics as a subject training organisational process. Historical principles and tendencies concerning subject-specialised school creation in particular as well as Russian and Soviet school practice are analysed in the article. The differentiation process experience on the high stage of school education in such countries as France, Japan and the USA has been investigated. The main functions of a subject matter mastering conception at high school have been pointed out. Mathematical education is considered to be the principal component of comprehensive education as well as the factor influencing the quality of education at a higher educational establishment on the whole run. The peculiarities of mathematical education content at a subjectspecialised school in different directions of mathematical training have been illuminated in the article along with the deep consideration of succession problem of both secondary comprehensive and higher school educational processes correspondingly, which, in their turn, are regarded as the possible ways of education quality improvement in terms of higher educational establishment (HEE). The constructional principles of educational courses in various mathematical subjects are defined in the article.
\end{abstract}

Keywords: a subject-specialised school, differentiating education, mathematical education, directions (vectors) in mathematics training, levels of mathematical education in high school, succession in education

Cite This Article: Irina Lovyanova, “On Specific Character of Mathematical Education Content Selection at Subject-Specialised School.” American Journal of Educational Research 1, no. 11 (2013): 523-527. doi: 10.12691/education-1-11-11.

\section{Introduction}

Specific character of modern system of education implies its ability not only to impart some knowledge to students but also to form their need in constant independent (self-directed) and creative approach to new mass of knowledge acquisition, create opportunities to apply their skills and abilities of independent work, prepare them to continue their study at HEE.

Modern school faces a range of educational objectives:

- to prepare students for further mature life and provide them with all necessary body of knowledge;

- to encourage students to acquire knowledge in an active way, to keep them interested in research activities during the process of education;

- to bring them up in the spirit of high moral ideals;

- to assist in their conscious choice of future profession;

- to help them enter the HEE they are aimed at and encourage for further education and self-education in HEE.

One of the vectors of modernisation is subject-specialization at comprehensive high school. School specialization into multi-subject specialised comprehensive institution is a strong demand of present day society. Subject training concept realisation has made it necessary to introduce certain additional innovations into school practice. It is important to emphasise that a student does not have to choose a certain profession on this stage but a circle of knowledge connected with his further professional sphere.

The analysis of historical regularities and tendencies in creation of a subject-specialised school allows of intelligent approaching the problem solution of a school subject-specialization in modern conditions. So, the analysis of Russian and Soviet school experience shows:

1) the subject-specialised differentiation of training can be carried out owing to availability of various types of educational institutions, thus each type of an institution has the curriculum and the programmes of their own (on mathematics in particular,);

2) the subject-specialised differentiation based on purely pragmatical grounds, without taking into account students' propensities and capacities, does not lead to positive results;

3) partial furcation, e.i. curricula and programmes variation concerning only one subject content, without radical restructuring of the whole curriculum and all educational programmes, is inexpedient.

Subject-specialised differentiation in such countries as France, Japan and the USA is carried out on the basis of half-furcation that is on the way of a possibly wider variety of biases and directions. Long and sufficient experience of educational differentiation of the senior link of secondary comprehensive school in France, Japan and the USA is characterized by the following: 
1) the abundance and variety of directions in educational process in the senior classes allow to consider propensities and capacities of practically all students, as well as demand of the state in different experts and specialists;

2) orientation of mathematical courses on this or that specialization is generally aimed at probably more significant satisfaction of students' capacities at mastering their major speciality (however any mathematical preparation on the higher level is based on the common feedback from the secondary link of comprehensive school system);

3) in our opinion, availability of plenty of optional mathematical courses in a combination to the minimal mandatory mathematical course, can provide inadequate base of mathematical education [[5], p.24].

On the basis of the analysis of world experience, the concept of secondary school mathematical education formation, as one of the world tendencies, can be pointed out as the way of understanding and realizing the importance of studying mathematics by all secondary school students. In fact only at availability of appropriating mathematical preparation in conditions of continuous formation the person can solve the problem on the further destiny whether it is a question of professional skills improvement, a process of a new vocation gaining, a speciality, a replacement of blanks of the previous grade level [3].

So, the idea of subject-specialised differentiation of training at the senior school is not new. Definitely it found its embodiment and was improved during long-term time in educational systems of many countries.

As the analysis of psychological-and-pedagogical literature and of school practice shows that some of the tasks caused by subject-specialization have been successfully solved at modern school and introduced into contemporary school practice.

So, the differentiated training is not something especially new to our school. In pedagogical researches it is revealed through different aspects of the problem, namely: the general problems of differentiation as the way of individualization (I.Lerner); creation of pedagogical conditions of differentiated training for students at a comprehensive school (O.Bratanich); development of different curricula (N.Guzik, B.Firsov); technology of multi-leveled differentiation in the process of mathematcs teaching (A.Kapinosov). Also it is necessary to note, that one of prototypes of the subject-specialised training is native schools" practice on the program "secondary school-higher school” [[10], p.3]. Here the richest operational experience which, in many respects, defines the general direction of activity of the senior link school is preserved and accumulated. The Learning efficiency in such classes serves a parameter of productivity of school practice in the social aspect.

Profile Education - kind of differentiated instruction, which takes into consideration the educational needs, aptitudes and abilities of students and create an environment for learning high school students in accordance with their professional self-determination, which is achieved through changes in the objectives, content and structure of the organization of training

Under differentiation understand the multiplicity and variety of individual measures to achieve agreed objectives of public education (A. Furman) [11].
Differentiation of training allows you to organize the learning process by taking into account the individual characteristics of the person; it provides mastering the content of education for all students when released invariant part.

In the context of succession of mathematical education in the system "secondary school-higher school" of higher learning deserves attention experience is accumulated by researchers on issue of selection of maintenance of mathematical education at high special school. In particular, we accent attention on researches of scientist from Belarus of L.I.Maysenya [8], in the doctoral dissertation of which methodological bases of the development of the students mathematical education at the vocational secondary education level, methodical system of the students' mathematical education, students' mathematical education concept at the vocational secondary education level of the Republic of Belarus and respective model of the contents of mathematical education were developed for the first time. The concept of mathematical education includes principles of mathematical education, the strategic goal of mathematical education, typological classification of mathematical education, levelling of all vocational secondary education specializations into three typological groups according to the types of mathematical education. In the developed concept of the subject of mathematics, the main approaches to the selection, systematization and adaptation of the mathematical contents were determined.

In accordance with the mathematical education concept, the complex methodological support of the mathematics teaching process (system presentation of the mathematical educations in the standards of specialities, a set of sample academic curricula for the subject of mathematics, and 6 teaching aids) for all the specialities of the vocational secondary education system of the Republic of Belarus.

In Ukraine there is a certain positive experience of introduction and functioning of subject-specialised training. Today in Ukraine there is a branched out network of different types of educational institutions: licea, grammar schools, collegiums, etc. These educational institutions provide a possibility of profound knowledge reception in certain directions. Popularity of training in licea and grammar schools proves, that demand for subjectspecialised training at the senior school is actually present.

One of the major conditions of effective realization of the problem of quality improvement in the process of mathematical education content selection is maintenance of continuity of its steps. The problem of continuity of school and maximum vocational training is not new to the pedagogical science. Psychological-pedagogical aspects of realization of continuity in training are considered in works by L.Bozhovich, L.Ziubin, N.Kuzmina, A.Leontiev, J.Samarin, A.Sokolov, N.Talyzina, etc. Questions of interrelation of a content of the general and vocational training are specified by S.Batyshev, A.Bondar, M.Godnik, V.Zagviazinsky, K.Zolotar, A.Kirsanov, A.Kobyliatsky, Y.Kustov, V.Ledniev, A.Mubarakov, A.Novikov, V. Poliakov, V.Popkov, D.Yagofarova, etc. The role of the process of training organization in the continuity of training is reflected in works by A.Beliaieva, O.Liseichikov, N.Mochalova, etc.

With acceptance of the Law of Ukraine "About the general secondary education” (1991 [4], “Concepts of the 
general secondary education (12-year school)" (2001 [7], "the National doctrine of progress of formation of Ukraine in XXI century" (2002 [9], "Concepts of subjectspecialised training at the senior school” (from 25.09.2003 and 11.09.2009) [6] in which introduction of subjectspecialised training at the senior school is legislatively approved, the present stage of the subject-specialised training problem is in progress, the organization of the process of continuity and improvement of quality of formation at all its steps has begun. As a result, the essence, objective, principles, as well as structure of subject-specialised training is certain, possible forms of the organization, a condition of complex educationalmethodological support are planned.

The concept of subject-specialised training at senior school defines the following problems:

1) creation of conditions for discovering and development of educational-cognitive and professional interests, propensities, capacities and demands of students of the senior school during their general educational preparation;

2) students' education and instruction of diligent attitude to work, maintenance of conditions for their vital and professional self-determination, formation of readiness for a conscious choice and mastering the future profession;

3) formation of students' social, communicative, information, technical, technological competences on presubject-specialization on the grade level, preparation for a choice of area of the future professional activities;

4) maintenance successional-perspective communications between the general average and vocational training according to the selected structure.

\section{Methodology of Research}

Mathematical education is an important component of general educational preparation. The quality of mathematical preparation of young generation is the indicator of readiness of a society to social and economic progress, to introduction of high technologies, mobility of the person. It is marked in State target social program of improvement of school quality on natural-mathematical education for the period till 2015, that priority directions of progress of mathematical education can become: personal orientation on education, complete display of components of the mathematical science in a school content of education, realization by methodical system of mathematics training of the basic functions of mathematical education.

Strategic direction of progress of mathematical education is maintenance of its high quality on all educational levels. Thus, the necessary condition of quality improvement of vocational training in high school is the formation of resistant professional interest with entrants during their school training.

High school students' orientation on the future profession gets special sense in connection with introduction of subject-specialised training.

The subject-specialised school is one of the basic stages in the system of continuous vocational training of future experts. And therefore, special attention to the problem of preparation of senior students for the future profession while studying specific subject matters of a school rate, in particular, requires mathematics. Directions in construction of training courses of mathematical disciplines which allow to design such rate for any subject-specialised direction are stated. We shall allocate some of them, namely: definition of a content of a training course according to the criteria of its selection; allocation of the priority is substantial-methodical line; carrying out of the didactic analysis of solved problems and allocation of the most illustrative examples for formation of new concepts and demonstrations of practical appendices of mathematics in the context of the given structure of training; selection of methods of teaching and the statement of a training course adequate to specific features-typological of students, as well as objectives and problems of studying mathematics in the given group of students [[10], p.9].

As for the definition of the content of a training course proceeding from tasks in view and according to the objective of subject-specialised training, it is necessary to allocate the following principles of selection of the content:

- principle of furcation (distribution of disciples according to the level of educational preparation, interests, demands, capacities and propensities);

- principle of variability and alternativeness (educational programmes, technologies of training and educational-methodological maintenance);

- principle of continuity and succession (between presubject-specialised preparation and subjectspecialised training, vocational training);

- principle of flexibility (the content and forms of the organization of subject-specialised training, including distance education; a possibility of the structure variation);

- principle of diagnostic-and prognostic realizations (revealing of disciples' capacities with the objective of their proved orientation to the structure of training).

\section{Discussion and Results}

Concentrating attention in our research on the process of mathematical preparation of senior students, it is necessary to note, that training to the mathematician within the limits of base subject-specialised mathematical preparation can have three directions: common cultural, applied and theoretical. This distribution is connected with the functions of the subject matter in realization of a structure features of training and in professional development of the person. That is why the content of mathematical education on each of these directions should conform to the specified functions of the subject.

So, from the perspective of a common cultural direction it is necessary to provide a level of mathematical education which will assist in formation of professionally meaningful qualities of the person according to the field of activity selected by the senior student in the future. As to the components of methodological system of professionally directed training mathematics we point out that in the conditions of personal orientation the content of education is maybe certain not only in terms of subject matter of mathematics, but also in terms of personal functions progress with the subjects of training - the disciple and the teacher. 
On an applied direction, the components of methodological system of mathematics training should assist in of personal functions progress of training subjects, in particular, to progress at disciples of logical thinking and spatial imagination, algorithmic, information and graphic culture, memory, attention, intuition; to disciples' mastering of mathematics language in oral and written forms, system of mathematical knowledge, educational skills and skills necessary in everyday life as well as future professional work, sufficient for successful mastering by other educational fields of knowledge and maintenance of the educational continuity. Thus communications of mathematics with subject-specialised subject matters amplify due to the decision of problems of an applied content, illustrations of application of mathematical concepts, methods and models in school rates of chemistry, biology, physics and technologies.

On the theoretical direction by display of the educational content of mathematical fundamental knowledge training, cognitive interest of senior students to the future trade during fundamental preparation from mathematical disciplines dramatically grows and develops; students' mathematical capacities evolve (skills to operate scientific mathematical concepts and facts, that is to apply and explain the phenomena in new situations; to apply ways of activity; to establish relationships of cause and effect, to make proper and laconic conclusions); creative activity of the person as a senior student is shaped.

Such approach to construction of the of training content allows not only to shape specific knowledge, students' skills, but also provides psychological support of the training process during which the importance of mathematics studying reveals, there are positive emotions in relation to the subject matter, the individual success of a disciple in studying the discipline is perfectly shaped.

The content of training should answer the features of educational activity (to components, structure, sequence of actions and operations) and to be coordinated with logic of communicating individual, private or general. The specific character of an individual (in some detail-sensitive image or the abstract important attitude and model of its fixing) influences the technology of expansion of educational material and its complexity.

Mathematics and the system of mathematical knowledge take special seat in the system of universal knowledge, carrying out a role of the language of a science, language of scientific researches.

In the concept of progress of mathematical education two general functions are allocated: formation by means of the mathematics, directed on progress of disciples; and actually mathematical education as a basis of the future vocational training. These functions get special sense in conditions of subject-specialization formations. As M.Burda stresses [2], mathematical knowledge which is not used in professional work by graduates of schools, will be forgotten. There will be only mathematical progress, the developed style of thinking. Therefore the greater attention should be given to the functions of formation by means of mathematics which consist of a direction on the subject matter content on forming the qualities of the thinking necessary for adaptation and adequate functioning of the person in a society, on mastering the mathematical device as means of statement and the solution of the problems of reality.

The thinking is shaped during educational activity which includes the interconnected components: 1) motivational (interests, demands, motives); 2) remediallyoperational (forms and style of thinking, ways and reference points of activity); 3) substantial (formal-logical and operative knowledge); 4) prognostic (decision-making, preparations of the program of activity, a prediction of result). Depending on the content of components in educational activity empirical (sensual-subjective) or theoretical (rational) generalizations [2] prevail.

Depending on what type of generalization prevails (skilled-inductive, deductive, substantial) each level of activity has sublevels: educational activity over which skilled-inductive generalizations dominate; educational activity over which deductive generalizations dominate; educational activity in which near-to inductive-deductive generalizations take place also substantial (theoretical), however they are not leaders; educational activity, in which leading substantial generalizations are made.

Design subject-specialised training of mathematics should consider two factors at least: substantial orientation and level of training [[1], p. 28].

During the senior school the mathematics study is differentiated into four levels: the level of standard, academic, subject-specialised and the level of profound mathematics studying. Each of them is controlled and carried out by a separate curriculum (Table 1).

Table 1. Levels of Studying Mathematics in Senior School

\begin{tabular}{|c|c|c|}
\hline Curriculum & Education Content & Relation to the future profession \\
\hline Standard Level & $\begin{array}{l}\text { it is directed at the students' perception of } \\
\text { mathematics as a component of general culture }\end{array}$ & $\begin{array}{l}\text { graduates are not supposed to continue studying } \\
\text { mathematics or somehow connected with the subject in } \\
\text { their professional sphere }\end{array}$ \\
\hline Academic Level & $\begin{array}{l}\text { wider content and higher requirements for } \\
\text { mastering the subject compared to the standard } \\
\text { level }\end{array}$ & $\begin{array}{l}\text { First of all, it is supposed for those cases when mathematics } \\
\text { is closely connected with the subject-specialised disciplines } \\
\text { and assists in their effective mastering; moreover, the } \\
\text { curriculum establishes senior students mathematical } \\
\text { education for those who have not made up their mind yet } \\
\text { concerning the sphere of their future spesialisation }\end{array}$ \\
\hline Subject-specialised Level & $\begin{array}{l}\text { it is directed on senior students' key competences } \\
\text { formation, gaining skills of independent scientific- } \\
\text { and-research activity, investigating and searching } \\
\text { activity, their intellectual, mental, creative, moral, } \\
\text { physical and social characteristics, their striving for } \\
\text { self-development and self-education }\end{array}$ & $\begin{array}{l}\text { provides studying subject-matter with orientation to the } \\
\text { future profession which is closely connected with } \\
\text { mathematics or its practical application }\end{array}$ \\
\hline $\begin{array}{l}\text { Level of Profound Mathematics } \\
\text { Study }\end{array}$ & assumes profound subject matte study & it is aimed at studying mathematics in Year 8-11 \\
\hline
\end{tabular}




\section{Conclusion}

The process of subject-specialization in terms of modern senior school has objective and natural character as well as long-term history. It is necessary to note, that for the present stage the progress of subject-specialized school features which were traced at different stages of subject-specialised training idea functioning in domestic and foreign pedagogics are characteristic, namely: the choice of type of school with bifurcation or polifurcation; consideration of differentiation as the principle of training; introductions of optional courses at the students' choice; the idea of succession between senior school by the secondary special education and higher school; the consideration of students' propensities and capacities, as well as demands of the state for experts of different areas.

The following ideas are referred to as the principles put into the basis of differentiation system while school training:

- introduction of training in directions, only after disciples receive a general base of education and will be defined in the further choice;

- at the senior step of training it is necessary to provide as many directions of training as possible;

- subjects pertinently unite in blocks by the principle of unity of objectives and problems of training in the selected direction;

- the mathematics should enter into the list of mandatory subjects of any structures (physical and mathematical, technical, humanitarian);

- realization of subject-specialised training of mathematics should be carried out in the view of its objectives, its features of the content and the form in comparison with training mathematics in general educational classes.

Problems of mathematics training at subject-specialised school are certain, namely:

- to provide a necessary common cultural level of mathematical preparation of youth that is defined by the society demand and abilities of students of the given age;

- to satisfy demands of subject-specialised preparation for progress of cognitive and mathematical activities of students, characteristic for the given structure;

- to shape means of mathematics professional propensities with students.

\section{Recommendations}

In conditions of subject-specialised senior school when mathematical preparation is conducted in different directions, such as common cultural, applied, theoretical, the specific character of mathematics training in each direction, from our point of view, should be under the construction taking into consideration the level given. At senior subject-specialised school note should be taken on the forms of educating in the context of succession of them with the forms of educating at higher school. The table of contents of educating to mathematics at high special school must have the applied and professional orientation. The offer steps in development of mathematical education will assist the increase of its quality on all stages of education. We consider the research prospects in the following aspects: allocation of levels of mathematical activity depending on the direction of mathematical preparation; comparison of the training content to the students' level of thinking and the level of their mathematical activity in which we wish them to train; consideration of the educational problem as the central link of educational mathematical activity. Researches in the allocated directions, in our opinion, will make for conditions of continuity of secondary school and high school education, which, in its turn, will positively affect the quality of preparation of future experts.

\section{References}

[1] Brodsky, Y, "Ways of content renovation in school mathematical education", Matematyka v shkoli, №1, 24-29, 2008.

[2] Burda, M, "Humanitarian orientation of Mathematics textbooks content", Of international scientific and practical conference, ACMI, Poltava, 2004, 50-52.

[3] Dubinchuk, Y.S, Slepkan', Z.I, Sobol', S.A, Filippova, S.N, "Compulsory results of education prove to be true", Matematika $v$ shkole, №3, 9-10, 1990.

[4] Law of Ukraine "On general secondary education". [Online]. Available: http://zakon2.rada.gov.ua/laws/show/651-14.

[5] Koliagin, Y.M, Tkacheva, M.B, Fedorova, N.Y, "Subjectspecialization differentiation of mathematics training", Matematika v shkole, №4, 21-27, 1990.

[6] "Concept of subject-specialised education at high school", Information anthology of Ministry of education and science of Ukraine, № 24, 3-15, 2003.

[7] "Concept of general secondary education (12-year school)", Information anthology of Ministry of education and science of Ukraine, № 2, 2-22, 2002.

[8] Maisenia, L.I, Theoretical and Methodical Bases of Development of Students' Mathematical Education: Vocational Secondary Education Level, abstract of dissertation on gaining scientific degree of Doktor of Pedagogy, Minsk, 2013, 56.

[9] "National Doctrine of education progress of Ukraine in XXI century", Osvita Ukrainy, № 6, 3-9, 2002.

[10] Samsonov, P.I, Methods of educational course structuring in algebra and basics of mathematics analysis for grades with different subject-specialization: Illustrated by the example of natural sciences specialization, abstract of dissertation on gaining scientific degree of Candidate of Pedagogy, Moscow, 2004, 18.

[11] Furman, A., "System differentiation of learning: concept, theory, technology," Education and Management, № 2, 13-17, 1997. 